\title{
Indignación online. La conversación digital del \#NiñasNoMadres en Argentina
}

\author{
Online outrageousness. The digital conversation around
} \#NiñasNoMadres in Argentina

\section{Marina Acosta}

Universidad de Buenos Aires, Buenos Aires, Argentina

macostaasociales.uba.ar

\section{Agustina Lassi}

Universidad Nacional de La Matanza, Buenos Aires, Argentina

alassidunlam.edu.ar

\section{Resumen}

En 2019, en la provincia Argentina de Tucumán, la madre de una niña de 11 años violada pidió la aplicación de la Interrupción Legal del Embarazo. El Estado dilató el procedimiento y la niña fue obligada a convertirse en madre contra su voluntad. Twitter se convirtió en el escenario de la protesta de miles de mujeres. El objetivo general de la investigación es analizar la conversación digital que se activó en torno al \#NiñasNoMadres. La metodología utilizada es el análisis de contenido combinado con el data mining (minería de datos) y programas de asistencia. Entre los principales hallazgos se destacan que la conversación alrededor del hashtag ha sido guiada por dos cuentas (individuales) y dos clusters de usuarias (periodistas y actrices) y que la tematización virtual expuso el padecimiento al que el Estado somete a niñas violadas y a las que niega o dilata el derecho a interrumpir su embarazo.

Palabras clave: Redes sociales; feminismo; tecnopolítica; \#NiñasNoMadres

\begin{abstract}
At the beginning of 2019, in the Argentine province of Tucumán, the mother of an 11-year-old girl who was raped requested the application of the Legal Pregnancy Termination Act. The State delayed the decision regarding the procedure and the girl was forced to become a mother against her will. Twitter became the stage to the protest of thousands of women. The goal of this research was to analyze the digital conversation activated around \#NiñasNoMadres. The methodology used was the content analysis combined with data mining and assistance softwares. Among the main findings, it can be said that the conversation has been driven by two individual accounts and two defined clusters ljournalists and actresses). Thus, the virtual thematization exposed the suffering to which the State forces those young girls who are raped and denies or delays the right to interrupt their pregnancy.
\end{abstract}

Keywords: Social Networks; feminism; technopolitics; \#NiñasNoMadres. 


\section{Introducción}

El 1 de febrero de 2019, el periódico argentino La Nación publicó un cuestionado y polémico editorial sobre el embarazo en niñas ${ }^{1}$. Fiel a su línea editorial, el conservador diario justificaba allí que las niñas de trece o catorce años se convirtieran en madres y criticaba a aquellos padres que veían al aborto como posibilidad. Su idea se insertaba en el contexto de la discusión por la despenalización del aborto en el país que se había dado el año anterior a raíz del debate parlamentario que finalmente no llegó a sancionar una ley.

El editorial se propagó rápidamente en las redes sociales y despertó una ola de repudio en Twitter que llegó desde distintos sectores sociales y políticos, incluidos los trabajadores y trabajadoras del mismo medio. Hasta Unicef ${ }^{2}$ y Amnistía Internacional ${ }^{3}$, desde sus cuentas, condenaron el texto y advirtieron que no había que "admirar" a las niñas que quedan embarazadas por violaciones- tal como planteaba el diario- sino que protegerlas.

En enero de ese año, en la provincia de Tucumán, la madre de una niña de 11 años abusada sexualmente pidió la aplicación de la Interrupción Legal del Embarazo (ILE). Un fallo de 2012, de la Corte Suprema de Justicia de la Nación, obliga a los estados provinciales a garantizar la interrupción del embarazo cuando este fuere producto de una violación. El procedimiento no es punible ni para la mujer que lo requiere ni para los profesionales que practican el aborto. Sin embargo, la decisión de la justicia tucumana fue dilatada. Lo que siguió luego fue una serie de irregularidades linadmisibles e ilegales) que derivaron en una cesárea a la niña cuando cursaba 23 semanas de embarazo. El sistema político y el sistema judicial la obligaron a ser madre contra su voluntad.

Otra vez, desde las redes sociales llegó la indignación. El hashtag \#NiñasNoMadres arropó la opinión de miles de mujeres que se mostraron enojadas y preocupadas por el caso de Tucumán. Como había ocurrido con otras cuestiones relacionadas a la violencia de género, en general, y al aborto en particular, Twitter se convirtió en el escenario de la protesta de las mujeres teniendo siempre como telón de fondo la necesidad de consensuar una norma para el aborto legal, seguro y gratuito.
En las sociedades de la información y el conocimiento, la acción colectiva suele tener como epicentro a las TIC (Castells, 2009; 2012). Esto permite afirmar, por un lado, el uso de las redes como herramientas de participación política y, por otro, que las TIC no son sólo un canal fundamental de expresión de los movimientos sociales sino además un componente relevante para comprender su configuración (Toret, 2013; 2015). Además, en las plataformas digitales se disputa la lucha por las narrativas y la interpretación discursiva (Fillieule \& Tartakowsky, 2015; Malini, 2017).

Es profusa la investigación sobre las formas de comunicación que utilizan las protestas sociales en red (Alcazan, 2012; Castells, 2012; Cruells \& Ibarra, 2013; Gerbaudo, 2012; 2016; Lago, 2012; Sádaba, 2012; Sádaba \& Gordo, 2008; Sorj \& Fausto, 2016; Treré \& Barranquero, 2013; Toret, 2013; 2015). El avance del feminismo y sus nuevas conquistas ha llevado también a focalizar en las posibilidades que ofrecen las plataformas digitales para el movimiento (Arias, 2017; Caro, 2015; Cook \& Hasmath, 2014; Fotopoulou, 2016; Núñez, Fernández \& Peña, 2016; Núñez \& Fernández, 2017; Sádaba \& Barranquero, 2019). En la academia argentina, no obstante, los trabajos aún son escasos (Acosta, 2018a; Acosta, 2018b; Laudano, 2017; Laudano, 2018b; Rosales, 2018). En este sentido, es relevante aportar investigación empírica a ese incipiente campo de estudio.

Esta investigación se pregunta ¿qué características adquirió la conversación digital, en Twitter, en el caso de la niña tucumana? El objetivo general de la investigación es analizar la conversación digital del \#NiñasNoMadres. En tanto, los objetivos específicos son: 1) describir la actividad de las principales cuentas; 2) establecer cómo se distribuyó la conversación para dar cuenta de la formación de las comunidades virtuales; 3 ) identificar la agenda temática.

\section{Marco referencial}

\subsection{Nuevos espacios de comunicación}

El ejercicio de la autocomunicación de masas se suma a la larga lista de ejemplos que advierten, desde hace un tiempo, un cambio en el paradig- 
ma de la comunicación. Desde el modelo clásico vertical del emisor-receptor se ha pasado a un sistema en el que múltiples actores se convierten en productores de mensajes que se amplifican por las redes de comunicación social en niveles globales y locales (Castells, 2009). Tal ejercicio expone, además, algunos presupuestos de las visiones optimistas de la cultura de la conectividad (Van Dijck, 2016). Acaso valga aquí la idea de que las redes permiten la apertura de nuevas vías para el ejercicio del derecho fundamental a la libertad de expresión.

Los desarrollos de la plataforma conocida como Internet hicieron resurgir la idea del ensanchamiento del espacio público, una gran plaza pública para la participación ciudadana que genera, indefectiblemente, un mayor acceso a la información pública (Goldberg, 2010; Norris, 2001; Sampedro, 2005). No obstante, reconocemos también dos grandes problemas que se derivan de la participación de los usuarios en las redes sociales. Por un lado, los efectos negativos de la censura que aplican (muchas veces) las plataformas digitales sobre la actividad de las cuentas, en determinadas situaciones, que deriva en el impedimento de expresarse con plena libertad (Van Dijck, 2016). Por otro, el fenómeno conocido como "cámara de eco", una metáfora que describe la tendencia creciente entre las comunidades de usuarios a consumir y amplificar aquellas informaciones/opiniones con las que están de acuerdo (Calvo, 2015; Jamieson \& Cappella, 2008; Rodríguez, 2017; Salaverría, 2017).

Los actores sociales recurren a las posibilidades que ofrecen las nuevas tecnologías de la comunicación para amplificar las bases de sustento de su protesta (Cammaerts, 2012; Cammaerts, Mattoni \& McCurdy, 2013; Casero-Ripollés, 2015; Castells, 2009; 2012; Welp, 2015). Por su naturaleza, las redes digitales siempre están abiertas y constituyen una nueva vía de participación ciudadana que, a su vez, cobra un nuevo valor en términos de activismo y deliberación sobre los asuntos públicos /del Campo \& Resina, 2010; Sampedro \& Resina, 2010; Resina, 2010).

Las tecnologías digitales de la autocomunicación de masas proporcionan a la acción colectiva un poderoso canal que permite, por un lado, la difusión y persuasión de sus acciones y, por otro, la conformación de su identidad pública y colectiva (Diez \&
Laraña, 2017, p.109). De allí que las organizaciones cuyo propósito sea generar cambios de actitudes y comportamientos vean a las plataformas digitales como espacios de comunicación (Sádaba \& Barranquero, 2019).

Frente a la idea de que los movimientos de protesta digitales son horizontales y carecen de líderes, señalamos, sin embargo, la importancia de los liderazgos para comprender su dinámica organizativa. Esos liderazgos -que ahora adquieren nuevas formas- cumplen una función determinante en tanto direccionan estratégicamente la acción colectiva en el espacio público digital (Gerbaudo, 2014; 2016).

\subsection{Tecnopolítica}

El espacio digital se presenta como una "nueva vía de participación" en la que la ciudadanía cobra un nuevo valor en términos de activismo y deliberación sobre los asuntos públicos. Al mismo tiempo, los medios de comunicación convencionales son cuestionados por su "déficit democrático" en la elaboración de la agenda-setting (del Campo \& Resina, 2010). Nos encontramos ante un nuevo escenario que deja atrás el momento reactivo frente a los nuevos medios para ingresar a un período propositivo y afirmativo que ve a las plataformas digitales como lugares donde también puede desarrollarse la actividad política (Cammaerts et. al, 2013; Sádaba, 2012).

La ciudadanía tiene el poder de politizar sus demandas y canalizar a través de Internet sus reclamos. Esta concepción se distancia de la propuesta que entiende al ciudadano como sujeto pasivo receptor de derechos. El 15M español, por citar un ejemplo, evidencia el rol de estos nuevos actores, en su mayoría jóvenes, que pudieron autoconvocarse ya sea por las plataformas digitales o telefonía móvil, para salir a la calle a reclamar por sus demandas ${ }^{4}$. Estos procesos manifiestan el poder de las redes como herramientas para empoderar a una ciudadanía que busca incluir su reclamo en la agenda política.

En el marco de la sociedad red, la ciudadanía se constituye también mediante las herramientas de debate, discusión y deliberación que ofrece la pro- 
Tabla 1. Ficha de recolección de datos

Ficha de Recolección de Datos

Variables relacionadas con la cuenta

\begin{tabular}{|l|l|l|l|l|}
\hline Cuenta & \multicolumn{3}{|l|}{ Nombre } & \\
\hline Descripción & \multicolumn{3}{|l|}{} \\
\hline Cuenta verificada (S/N) & & Alta en Twitter & \\
\hline Cuenta Protegida (S/N) & & & \\
\hline Variables relacionadas con la actividad de la cuenta & \\
\hline Tuits Publicados & & RT de unidad de analisis & \\
\hline Cantidad de seguidores & & FAVS de unidad de analisis & \\
\hline Cantidad de Seguidos & & & \\
\hline
\end{tabular}

Fuente: Elaboración propia.

pia arquitectura de Internet. Asimismo, los acontecimientos digitales que allí se producen conllevan una fuerte dimensión performativa; es decir, "crean con antelación en el digital, el mundo que se quiere vivir en el mundo físico" (Toret, 2013, p. 51).

Tales desarrollos tienen como telón de fondo teórico a la tecnopolítica que "se basa en la comprensión masiva, intuitiva y profunda de la capacidad política de organizarnos en red mediados por la tecnología (...)" (Toret, 2015, p. 63). Se trata, en efecto, del uso estratégico de las herramientas digitales para la organización, comunicación y acción colectiva (Toret, 2013, p. 20). El concepto recuerda, por cierto, a la autocomunicación de masas donde los usuarios, en las plataformas digitales, generan sus propios sistemas de comunicación (Castells, 2009) lo que permite, a su vez, un patrón de autoorganización política en la sociedad red (Alcazan, 2012; Guitérrez, 2014; Jurado, 2013).

\section{Metodología}

Esta investigación recurre al clásico análisis de contenido $(A C)$ que permite, a través de ciertos datos, realizar inferencias reproducibles y válidas que puedan aplicarse a un contexto (Krippendorf, 1990, p.28). Combinamos el AC con el data mining (minería de datos) para extraer y organizar información que no es posible obtener mediante méto- dos estadísticos convencionales. El data mining no sólo permite vencer las limitaciones del AC tradicional sino, además, conseguir mayores muestras y mejor codificación de datos.

Los datos fueron recolectados utilizando la aplicación Twarc realizada bajo Phyton que permite conectarse directamente a la red de Twitter mediante una API (Application Programming Interface). La estrategia de captura se definió bajo el término $\mathrm{Ni}$ ñasNoMadres que coincide con el principal hashtag de difusión en los días comprendidos entre el 25 de febrero y el 6 de marzo de 2019.

Los mensajes fueron curados para concentrarnos en los tuits que contuvieran las siguientes palabras: madres, niñas, embarazo, violación y Tucumán. La codificación de los datos de las cuentas más relevantes la hemos realizado mediante una ficha de recogida de datos:

Una vez obtenidas las principales cuentas con actividad se aplicó la observación directa de esos perfiles de Twitter en la página oficial junto con la observación de las reacciones generadas y el análisis de los 10 hashtags más representados. La muestra recolectada con Twarc se volcó en archivos ".txt" para que pudiesen ser reconocidos por la herramienta de análisis Voyant-Tools. Esta herramienta brinda un ambiente para la lectura y análisis de textos digitales y permitió el abordaje cuantitativo del uso de palabras clave en los tuits. Para asistir al análisis cualitativo de ese proceso recurrimos a 
ATLAS/ti, en su versión 8, para recopilar y clasificar datos en una misma unidad hermenéutica y construir una red semántica que posibilitó la comprensión global de la conversación digital.

Finalmente, para dar cuenta de la formación de comunidades digitales se utilizó Gephi que permitió elaborar el grafo (conjunto de nodos y aristas) de la conversación del \#NiñasNoMadres. En el análisis, los usuarios centrales (nodos) se enlazan (aristas) con otros usuarios (nodos) y constituyen la subestructura de la expansión de la red estudiada (Giraldo-Luque, Fernández-García \& PérezArce, 2018). Las relaciones entre nodos y aristas son esenciales para construir datos sobre la articulación, densidad, organicidad y la conectividad de una determinada red (Abrego, Bona \& Reguillo, 2018). Las comunidades se generan cuando dos o más nodos interactúan entre sí con distintos grados y pesos. La construcción de un grafo permite la visualización de características importantes que difícilmente pueden analizarse únicamente en una tabla de datos (Abascal, López \& Zepeda, 2015).

Cuando se realizan estudios sobre hashtags operan diferentes sesgos. En la actual investigación el principal sesgo es que sólo se analizan las interacciones que la API de Twitter decide mostrar. Por otro lado, lo que los usuarios expresan en esta plataforma digital no constituye una muestra representativa de la población. Asimismo, es relevante recuperar la condición de publicidad con relación al contenido de los tuits que forman parte de este trabajo. La plataforma plantea en sus términos de servicio que todos los datos enviados a través de Twitter podrían ser utilizados por terceros ${ }^{5}$.

\subsection{Twitter}

En Argentina, la penetración de Internet asciende al $93 \%$. Junto a Brasil lidera en engagement con un promedio diario de 3 horas 34 minutos en el uso de redes sociales. Los usuarios argentinos de internet usan mucho las redes sociales (76\%): YouTube es la red social más utilizada con un $93 \%$, seguida por Facebook con una penetración del 91\%, Instagram con $68 \%$ y Twitter con el $46 \%$ (Hootsuite \& We are social, 2019). Por cierto, el Informe 2017 de Latinobarómetro señala que las redes sociales se han convertido para un tercio de la población de América Latina en una fuente de comunicación política sustituyendo medios formales.

Desde 2009, Twitter ha despertado un gran interés en diferentes campos de las ciencias sociales (Christensen, 2011; Lovejoy, Water \& Saxton, 2012; Orihuela, 2011; Van Dijck, 2016). Fueron, no obstante, los episodios de la Primavera Árabe en 2011 los que encendieron las alarmas en la academia sobre el potencial que esta plataforma podía tener para el activismo político (Bastos, Mercea \& Charpentier, 2015; Castells, 2009; 2012; Soengas, 2013).

La disputa por la interpretación encuentra en los hashtags su eje de articulación. Se trata de una etiqueta (creada por los propios usuarios) que agrupa contenidos. Poseen una dimensión performativa; es decir, “hablan por sí mismos, para sí y para otros con la finalidad de extender el acontecimiento entre los ecos de la retroalimentación mediática global" (Toret, 2013, p. 62).

\subsection{Composición de la muestra}

La muestra se compone de un total de 92.780 tuits, con 20.695 usuarios activos y la utilización regular de 20 hashtags. Por su alto nivel de engagement, fueron identificados 1.264 usuarios. Las unidades de análisis fueron los tuits individuales.

\section{Análisis de los resultados}

Durante el período estudiado se analizaron 92.780 acciones en Twitter Argentina destinadas a la comunicación de mensajes en torno al hashtag \#NiñasNoMadres $(66,85 \%)$. Los hashtags que más veces acompañaron la temática principal fueron: \#ILEyaEsDerecho (13,31\%), \#Tucumán (4,5\%), \#URGENTE (1,03\%), \#Alos11Años (0,98\%), \#Argentina (0,96\%), \#FueraChahala $(0,75 \%)$, \#AbortoLegalYa (0,72\%), \#CesáreaNoEs/LE $(0,60 \%)$ y \#FueraVigliocco $(0,56 \%)$. La media ronda las 34 palabras y el uso de hashtags en 1,32 por tuit. Es decir, a razón de un hashtag por publicación. Del total de tuits recolectados, el $59 \%$ contuvo al menos un hashtag. 
Figura 1. Picos de acción

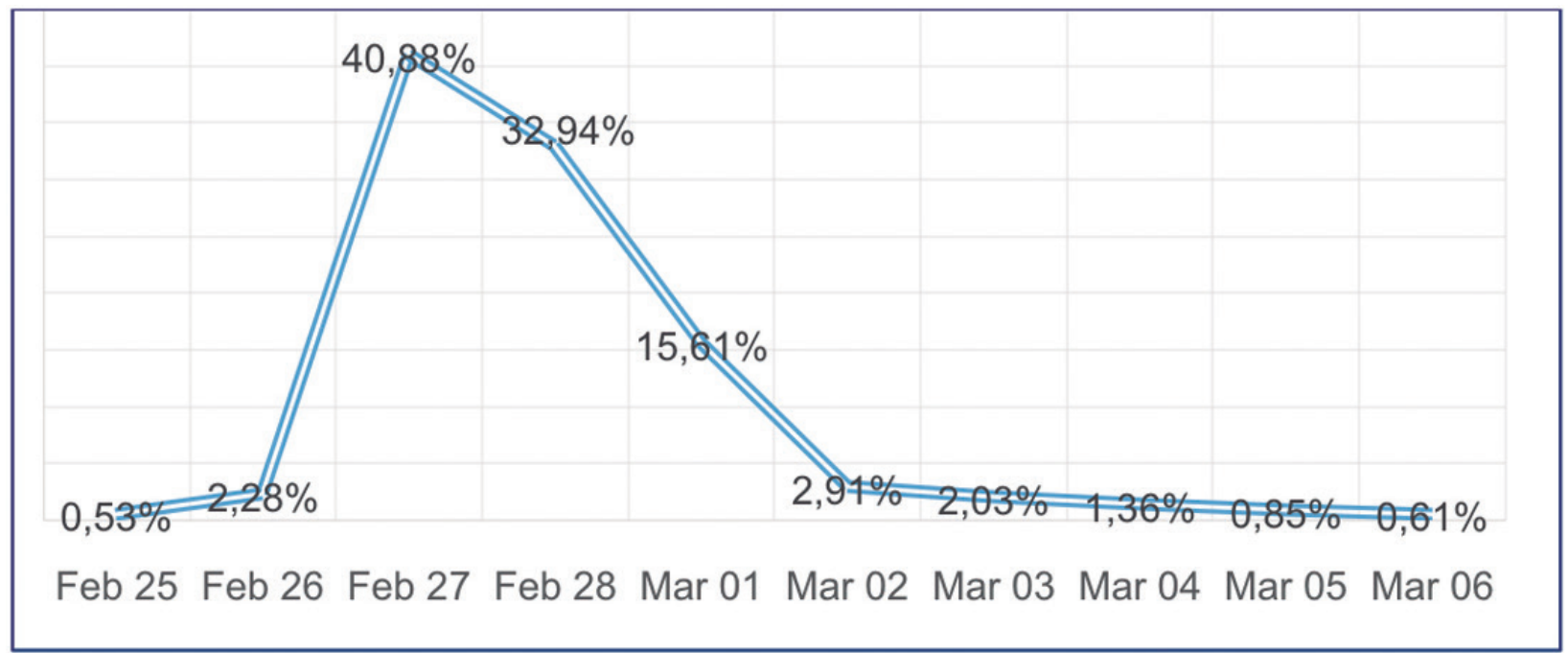

Fuente: Elaboración propia.

En lo que respecta al tiempo y al impacto diario de los tuits, el 27 y el 28 de febrero de 2019 representan los días con mayor actividad de tuits. Luego de esas fechas, el \#NiñasNoMadres comenzó a perder fuerza y la conversación se diluyó (ver Figura 1).

Como se observa en la Figura 1, el día 27 de febrero se generó el $40,8 \%$ de los tuits mientras que el día posterior, el 32,9\%. El pico de acción coincide con el día en que se dio a conocer la noticia de que a la niña le habían practicado una cesárea. Para dimensionar la tortura a la que fue sometida, el 28 de febrero, el colectivo de Actrices Argentinas lque lucha entre otras cosas por la despenalización del aborto en Argentinal lanzó una iniciativa en las redes: \#YoAlos11años. Se trataba de compartir una foto de cada una de ellas a esa edad acompañada del \#NiñasNoMadres. La acción se volvió viral en Twitter e Instagram.

Entre el 27 de febrero y el 1 de marzo de 2019 se registró el $89,4 \%$ de actividad. Los términos más utilizados fueron: [11 años] (36\%); [Niña] (10,3\%); [Argentina] (10,3\%); [Tucumán] (7,8\%); [Tortura] (7\%) y [Violación] $(5,6 \%)$. Por caso, el tuit de la cuenta ACamila_denti que obtuvo elevada cantidad de retuits (RT), considera la mayor acción de viralización del tema $(10,7 \%)$ :

Anoche la obligaron a parir en Tucumán. Es una niña de 11 años y fue violada. Le practicaron una cesárea pese a la oposición de su familia.
Durante dos meses pidió que le saquen lo que le metió el viejo adentro, la ignoraron. Ustedes son militantes de la tortura. \#NiñasNoMadres. (Fuente: Twitter)

\subsection{Actividad de las principales cuentas}

Dentro del numeroso universo de usuarios (20.695) que registraron actividad en el \#NiñasNoMadres, se observó en particular la de los 1.264 que recibieron RT de al menos dos usuarios (grado superior a 2.0 de aristas). Además, se restringió el análisis a aquellas cuentas que registraron un nivel superior a las 3.000 reacciones entre RT, comentarios y favoritos (FAV). La siguiente tabla expone las cuentas de las nueve usuarias de la muestra que cumplieron con estos requisitos:

La cuenta Acamila_denti, primera en el ranking de usuarios con mayor cantidad de reacciones y de RT únicos (no añaden comentarios al contenido original), adjuntó una imagen de una niña con un pañuelo celeste (símbolo de la posición provida) cubriéndole la boca. Se convirtió en el tuit con más reacciones $(28,14 \%)$. Con un caudal relativamente pequeño de seguidores pero utilizando un contenido de fuerte impacto recibió el mayor porcentaje de reacciones. La estrategia fue interesante: la imagen además de aportar una información del mundo tiene un valor de signo; es decir, represen- 
Tabla 2. Cuentas con altos niveles de actividad

\begin{tabular}{|l|l|l|l|}
\hline Cuenta & Cantidad de Seguidores & $\begin{array}{l}\text { Reacciones } \\
\text { (RT+FV+Comentarios) }\end{array}$ & Reacciones \% \\
\hline Acamila_denti & 364 & 26061 & 28.14 \\
\hline acharolopez & 148000 & 21067 & 22.74 \\
\hline achinasuarez & 3780000 & 10341 & 11.16 \\
\hline aflorencialcaraz & 31600 & 8611 & 9.30 \\
\hline aCaritoMorales04 & 3846 & 6334 & 6.84 \\
\hline Asoythelmafardin & 114000 & 6252 & 6.75 \\
\hline abaronjimena & 2390000 & 5830 & 6.30 \\
\hline Assoyingridbeck & 139000 & 5005 & 5.40 \\
\hline aMarian_Carbajal & 23700 & 3125 & 3.37 \\
\hline Total & 6630510 & 92626 & 100 \\
\hline
\end{tabular}

Fuente: Elaboración propia.

ta un contenido cuyos caracteres no refleja visualmente. En tanto operan a favor de una economía narrativa, las imágenes tienen el poder de evocar y condensar varios significados. Con su publicación, la usuaria llamó la atención sobre el debate que debe volver a darse por la despenalización del aborto en Argentina. Este contenido resulta también relevante puesto que fue difundido desde una cuenta no reconocida y a título personal.

La cuenta ACharolopez pertenece a una actriz, cantante y humorista argentina que forma parte activa del colectivo Actrices Argentinas, también recibió una alta cantidad de reacciones $(22,7 \%)$. En este caso, su tuit rezaba:

A los 11 años no podes votar, conducir, comprar alcohol ni puchos, no podes alquilar un monoambiente. Peeero si podes ser madre que es re mil más difícil complicado doloroso y traumático que hacer todas esas cosas a la vez. \#NiñasNoMadres. (Fuente: Twitter).

En tercer lugar, se ubicó la actividad de la cuenta achinasuarez, de una popular actriz argentina, integrante del colectivo Actrices Argentinas. En este caso, el contenido del tuit que provocó gran cantidad de reacciones $(11,16 \%)$ se relacionaba con su foto en el marco de la iniciativa \#YoALos 11.

Finalmente, la cuenta Aflorencialcaraz, de una escritora y periodista argentina con más de 30 mil seguidores, se posicionó en el cuarto lugar de engagement $(9,3 \%)$. En su tuit recordó otro caso de características similares:
Al igual que en Jujuy, anoche se practicó una cesárea a la niña de 11 años víctima de violación en Tucumán. La dilación a la que la sometieron es tortura, la cesárea una vulneración de sus derechos, someterla a crecer criando después de una violación es una condena \#NiñasNoMadres. (Fuente: Twitter).

\subsection{La conversación digital}

El análisis de comunidades revela datos que aportan información adicional para comprender la conversación en torno al hashtag investigado. Gephi detectó un total de 16.427 nodos y 19.022 aristas. La Figura 2 visualiza y distingue los nodos en torno a la actividad de las cuentas que se describieron en el apartado anterior. Se aplicaron los filtros componente gigante y $\mathrm{K}$-core a la clasificación para observar los grupos más grandes de nodos conectados. Luego, a través del algoritmo de layout Force Atlas 2 , se graficó la interacción dirigida entre usuarios y se obtuvieron las imágenes nodales.

El nodo que pertenece al tuit de Aacamila_denti muestra pocas relaciones de componentes conectados que se explica por su baja cantidad de seguidores y su alto nivel de engagement para la unidad analizada. Son elevadas las conexiones comunales entre las cuentas de los demás usuarios como puede observarse en la parte superior del grafo donde el nivel de organicidad en las interacciones entre nodos demuestra la fuerte conectividad entre comunidades. 
Figura 2. Grafo de interacciones

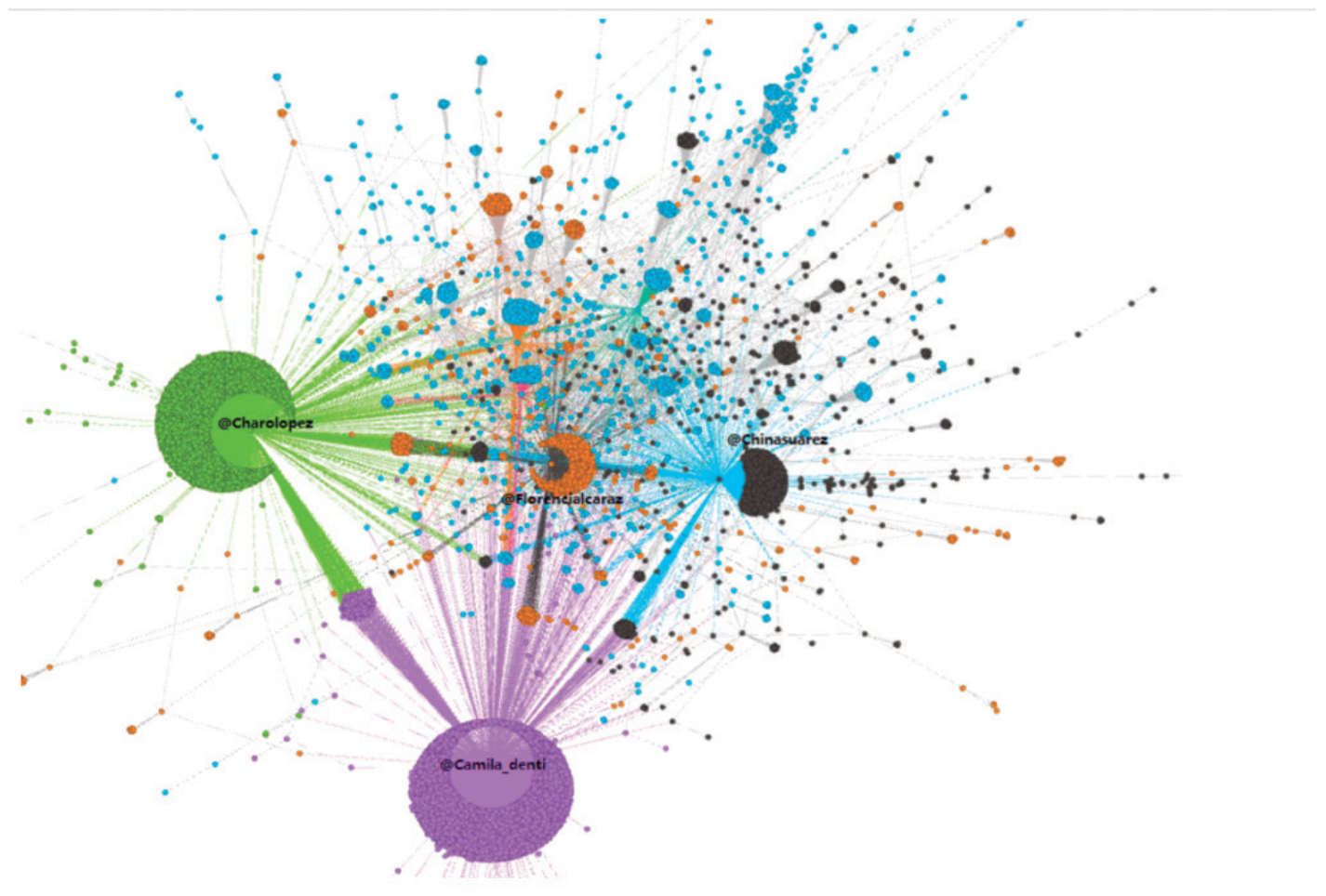

Fuente: Elaboración propia a partir de los datos proporcionados por Gephi.

La visualización de los colores aporta otros datos: a) violeta y verde: representan la actividad de las dos cuentas con más reacciones (Iacamila_denti; aCharolopez); b) celeste: representa la actividad del colectivo Actrices Argentinas con la iniciativa \#YoAlos 11; cl negro, naranja y rosa: están relacionados con el grupo de periodistas liderado por las cuentas Aflorencialcaraz; Assoyingridbeck y laMarian_Carbajal, el cual tuvo un papel muy activo en los inicios del \#NiUnaMenos en 2015 y se convirtió en referente de la lucha contra la violencia de género. Los grupos de colores b y c lactrices y periodistas) basaron su tematización en el pedido de respeto a la legislación vigente (ILE), la denuncia de la intromisión del Estado y la Iglesia y el uso de fotografías a los once años.

\subsection{Agenda temática}

Para comprender la geografía discursiva del \#NiñasNoMadres, la herramienta ATLAS/ti nos ha permitido identificar, en las publicaciones de los usuarios, un conjunto de palabras clave lcódigos y citas) que relacionamos en una red semántica.
Con ello, damos cuenta de la agenda temática que se activó.

Los conceptos que se reiteraron en la conversación digital sobre el caso fueron: violación (42.286 repeticiones) y tortura (27.877 repeticiones). El primero recalcaba que la niña había sido víctima de un abuso por lo que era necesario que se aplicara la ILE. El segundo se corresponde con la impresión generalizada de las usuarias sobre el padecimiento que sufrió al obligarla a ser madre. Los hashtags que acompañaron esta discusión fueron: \#Yoalos11años, \#CesáreaEsTortura, \#TucumánJardinDeLaTortura, \#ILEYaEsDerecho \#NoFuelLEFueTortura y \#CesáreaNoEsILE.

La iglesia fue blanco de recriminaciones 11.470 repeticiones); en particular, las declaraciones del arzobispo de Tucumán, Carlos Sánchez (2.284 repeticiones) que despertaron una ola de repudio. El clérigo había llamado a los feligreses a "custodiar" el feto de la niña, además de hacer público su nombre (violando así su derecho a la intimidad). Los hashtags utilizados: \#IglesiaYEstadoAsuntoSeparado, \#SalvemosAllnocente, \#TorturadoresDeNiñas y \#DerechoADecidir. 
Figura 3. Red semántica

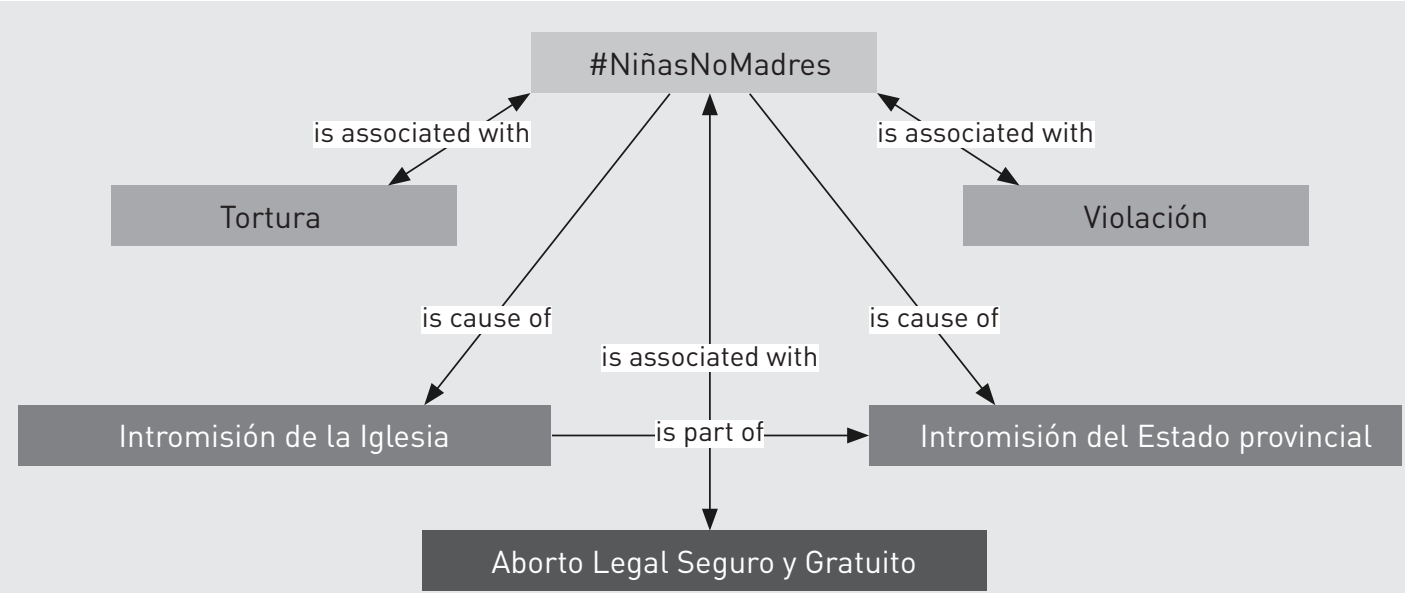

Fuente: Elaboración propia.

Hubo reproches, también, al Estado provincial (1.266 repeticiones). Los cuestionamientos se dirigían al sistema de salud de la provincia y a su gobernador, Juan Manzur, a quienes se responsabilizaba de no garantizar a la niña el derecho a interrumpir su embarazo y continuarlo contra su voluntad. Las críticas se concentraron en las actuaciones de dos funcionarios públicos de Tucumán: la ministra de Salud Pública, Rossana Chahla, y el secretario ejecutivo médico, Gustavo Vigliocco. Los hashtags relacionados fueron: \#ElEstadoEsResponsable, \#FueraChahla y \#FueraVigliocco.

Finalmente, como había ocurrido en todo 2018, las usuarias insistieron en la necesidad de contar con una legislación sobre el aborto legal, seguro y gratuito, luego de la frustrada sanción de la ley durante ese año (4.051 repeticiones). Para hablar de este tema se incluyeron los hashtags: \#AbortoLegalYa, \#AbortoLegalSeguroYGratuito, \#Embarazolnfantil y \#QueSeaLey. Esta temática también fue relacionada con la de la violencia de género bajo los hashtags: \#NiUnaMenos, \#VivasNosQueremos, \#MiraComoNosPonemos y \#NoEsNo.

\section{Conclusiones}

En los últimos años, el movimiento feminista argentino ha experimentado un conjunto de cambios respecto de la comunicación de sus acciones. La irrupción del \#NiUnaMenos mostró que las plataformas digitales no son sólo lugares para la de- liberación sino además espacios desde donde se pueden plantear temas para la agenda pública e idear planes de acción para el desarrollo de las estrategias de lucha. Por cierto, ese movimiento logró visibilizar un tema preocupante para la sociedad argentina además de definir un conjunto de demandas por cambios políticos y culturales tendientes a revertir el maltrato cotidiano al que muchas mujeres están sometidas.

Las redes sociales, en efecto, se han convertido en el escenario de la protesta de las mujeres. A través de campañas de tecnopolítica, el feminismo proporcionó marcos interpretativos (frames) que activaron un intenso proceso de discusión pública sobre la violencia de género (Acosta, 2018b; Laudano, 2017; 2018a; 2018b; Rosales, 2018), el aborto (Acosta, 2018a) y la maternidad en niñas violadas. Respecto de esta última problemática, el \#NiñasNoMadres expuso el sufrimiento al que el Estado somete a aquellas niñas que son violadas y a las que niega el derecho a la interrupción legal del embarazo.

La investigación ha llamado la atención sobre la importancia de los liderazgos para comprender la dinámica organizativa de los movimientos en las redes. Esos liderazgos, que tienen ciertas consonancias con las reflexiones lazarsfeldianas, adquieren nuevas formas y cumplen una función determinante en tanto direccionan estratégicamente la acción colectiva en el espacio público digital (Gerbaudo, 2014; 2016). Por caso, a través de las métricas de centralidad, se ha demostrado que 
la conversación digital alrededor del \#NiñasNoMadres ha sido guiada por dos cuentas (individuales) y dos clusters de usuarias (periodistas y actrices).

Un dato imposible de soslayar es que el 7 de marzo de 2019, la Oficina para América del Sur del Alto Comisionado de las Naciones Unidas para los Derechos Humanos (ACNUDH) señaló que en el caso de la niña tucumana obligada a ser madre hubo "tortura y malos tratos". Como se advirtió, varios días antes en la conversación digital, la palabra tortura ya aparecía como uno de los principales términos que las cuentas utilizaban para posicionarse frente al caso.

\section{Notas}

1 Fuente:https://www.lanacion.com.ar/opinion/ninasmadres-con-mayusculas-nid2216199. Consulta: Abril de 2019.
2 Fuente:https://twitter.com/UNICEFargentina/ status/1091386957375197184?s=20 Consulta: abril de 2019

3 Fuente: https://twitter.com/amnistiaar/ status/1091410636976898048?s=20 Consulta: abril de 2019

4 El 15M también es conocido como el movimiento de ciudadanos Indignados. Surgió en Madrid, durante 2011, en un contexto de crisis de representación política que criticaba, entre otras cosas, los modos tradicionales de hacer política y la corrupción del sistema de partidos español. Se convirtió en el exponente de la organización y movilización ciudadana a través de la red (Cruells \& Ibara, 2013; Sampedro \& Sánchez, 2011; Sampedro, Sánchez \& Politti, 2013).

5 “Usted es responsable del uso de los Servicios, de cualquier Contenido que publique en los Servicios y de cualquier otra consecuencia que esto origine. La mayor parte del Contenido que usted envíe, publique o exponga a través de los Servicios de Twitter es público por defecto y podrá ser visto por otros usuarios y a través de servicios y sitios web de terceros". Fuente: https://twitter.com/es/ tos/previous/version_10 Consulta: diciembre de 2019

\section{Referencias}

Abascal, R., López, E. \& Zepeda, S. (2015). Identificación de influyentes en twitter a través del análisis textual y la elaboración de grafos. Pistas Educativas, 112, 1676-1693.

Abrego, V.H., Bona, Y. \& Reguillo, R. (2018). “Inteligencia artificial electoral. Tercer \#DebatelNe a la Presidencia". En: Molina, V., Macías, E., Beauvois, Y., Migues, H., Lima, S., Mejía, I.\& de la Peña, F. El efecto AMLO. Guadalajara: ITESO.

Acosta, M. (2018a). Ciberactivismo feminista. La lucha de las mujeres por la despenalización del aborto en Argentina, Sphera Publica, 2, (18), 2-20.

Acosta, M. (2018b). “Violencia de género y tecnopolítica. La génesis del \#NiUnaMenos en Argentina”. En Las formas de violencia en América Latina contemporánea. Buenos Aires: El Aleph.com.

Alcazan, A. (2012). Tecnopolítica, Internet y R-evoluciones. Barcelona: Icaria.

Arias, A. (2017). La cimentación social del concepto mujer en la red social Facebook. Revista de Investigación Educativa, 35 (1), 181-195.

Bastos, M., Mercea, D. \& Charpentier, A. (2015). Tents, Tweets, and Events: The Interplay Between Ongoing Protests and Social Media. Journal of Communication, 65, 320350.

Calvo, E. (2015). Anatomía política de Twitter en Argentina. Tuiteando\# Nisman. Buenos Aires: Capital Intelectual. 
Cammaerts, B., Mattoni, A. \& McCurdy, P. (Eds.) (2013). Mediation and protest movements. Bristol: Intellect.

Cammaerts, B. (2012). Protest logics and the mediation opportunity structure. European Journal Communication, 27 (2), 117-134.

Caro, L. (2015). Construir y comunicar un "nosotras" feminista desde los medios sociales. Una reflexión acerca del "feminismo del hashtag”. Commons, 4 (2), 124-154 https://revistas.uca.es/index.php/cayp/article/view/3098

Casero-Ripollés, A. (2015). Estrategias y prácticas comunicativas del activismo político en las redes sociales en España. Historia y Comunicación Social, 20 (2), 533-548.

Castells, M. (2009). Comunicación y poder. Madrid: Alianza.

Castells, M. (2012). Redes de indignación y esperanza. Madrid: Alianza.

Christensen, C. (2011). Twitter Revolutions?. Addressing Social Media and Dissent. The Communication Review, 14 (3), 155-157. DOI: 10.1080/10714421.2011.597235

Cook, J. \& Hasmath, R. (2014). The discursive construction and performance of gendered identity on social media. Current Sociology, 62 (7), 975-993. https://doi. org/10.1177/0011392114550008

Cruells, M. \& Ibarra, P. (Eds.) (2013). La democracia del futuro: Del 15 M a la emergencia de una sociedad civil viva. Barcelona: Icaria.

Del Campo, E. \& Resina, J. (2010). “Redes sociales, ciberpolítica y nuevas movilizaciones: el impacto digital en los procesos de deliberación y participación ciudadana". Ponencia presentada en el X Congreso Español de Sociología, Universidad Pública de Navarra, Pamplona, España.

Diez, R. \& Laraña, E. (2017). Democracia, dignidad y movimientos sociales. El surgimiento de la cultura cívica y la irrupción de los indignados en la vida pública. Colección Monografías, Núm. 308. Madrid: CIS.

Fillieule, 0. \& Tartakowsky, D. La manifestación. Cuando la acción colectiva toma las calles. Buenos Aires: Siglo XXI.

Fotopoulou, A. (2016). Digital and networked by default? Women's organisations and the social imaginary of networked feminism. New Media and Society, 18 (6), 1-17. https://doi.org/10.1177/1461444814552264

Gerbaudo, P. (2012). Tweets and the streets. Social media and contemporary activism. London: Pluto Press.

Gerbaudo, P. (2014). The persistence of collectivity in digital protest. Information, Communication \& Society, 17 (2), 264-268.

Gerbaudo, P. (2016). Social media teams as digital vanguards: the question of leadership in the management of key Facebook and Twitter accounts of Occupy Wall Street, Indignados and UK Uncut. Information Communication \& Society, 20 (2), 185-202. https://doi.org/10.1080/1369118X.2016.1161817 
Giraldo-Luque, S., Fernández-García, N. \& Pérez-Arce, J. C. (2018). La centralidad temática de la movilización \#NiUnaMenos en Twitter. El profesional de la información, 27 (1), 96-105.

Goldberg, G. (2010). Rethinking the public/virtual sphere: The problem with participation. New Media \& Society, 15, 739-754.

Guitérrez, A. (2014). Tecnopolitica. El uso y la concepción de las nuevas herramientas tecnológicas para la comunicación, la organización y la acción política colectiva. Madrid, España: Gutierrez Rubí. Recuperado de: http://www.gutierrezrubi.es/ wpcontent/uploads/2014/11/Tecnopol\%C3\%ADtica.pdf

Hootsuite \& We are Social (2019). Global Digital 2019 Report. [En línea]. Recuperado de: https://wearesocial.com/global-digital-report-2019

Jamieson, K.H., \& Cappella, J.N. (2008). Echo chamber: Rush Limbaugh and the conservative media establishment. Oxford: Oxford University Press.

Jurado, F. (2013). Tecnopolítica, redes y movimientos sociales. De la revolución en las comunicaciones al cambio de paradigma. Sevilla: Universidad Pablo de Olavide.

Krippendorff, K. (1990). Metodología de análisis de contenido. Teoría y práctica. Barcelona: Paidós.

Lago, S. (Comp.) (2012). Ciberespacio y Resistencias. Exploración en la cultura digital. Buenos Aires: Hekht.

Laudano, C. (2017). Movilizaciones \#NiUnaMenos y \#VivasNosQueremos en Argentina. Entre el activismo digital y el \#FeminismoLoHizo. Seminário Internacional Fazendo Gênero 11 \& 13th Women's Worlds Congress (Anais Eletrônicos), Florianópolis. Recuperado de: http://www.wwc2017.eventos.dype.com.br/resources/anais/1503871106_ARQUIVO_Laudano_Texto_completo_MM_FG.pdf.

Laudano, C. (2018a). “Acerca de la apropiación feminista de TICs”. En Chaher, S. (comp.). Argentina: medios de comunicación y género. ¿Hemos cumplido con la plataforma de acción de Beijing? Buenos Aires: Asociación Civil Comunicación para la Igualdad.

Laudano, C. (2018b). El grito que tiño las redes. Revista Bordes, 11, 59-66 Recuperado de: http://revistabordes.com.ar/el-grito-que-tino-las-redes/.

Lovejoy, K., Waters, R. y Saxton, G. (2012). Engaging stakeholders through Twitter: how nonprofit organizations are getting more out of 140 characters or less. Public Relations Review, 38, 313-318.

Malini, F. (2017). La Internet y la calle: ciberactivismo y movilización en las redes sociales. México: ITESO.

Norris, P. (2001). Digital divide. Civic engagement, information, poverty and the Internet Worldwide. Cambridge: Cambridge University Press.

Núñez, S., Fernández, D. \& Peña, P. (2016). Ciberactivismo contra la violencia de género: fetichismo tecnológico e interactividad. Feminismo/s, 27, 177-195. 
Núñez, S. \& Fernández, D. (2017). Narrativas transformadoras y testimonio ético: las estrategias discursivas de la Plataforma Feminista 7N, Contra las Violencias Machistas. index.comunicación, 7 (3), 269-281. Recuperado de: http://journals.sfu. ca/indexcomunicacion/index.php/indexcomunicacion/article/view/31

Orihuela, J.L. (2011). Mundo Twitter: una guía para comprender y dominar la plataforma que cambió la red. Barcelona: Alienta.

Resina, J. (2010). Ciberpolítica, redes sociales y nuevas movilizaciones en España: el impacto digital en los procesos de deliberación y participación ciudadana. Mediaciones Sociales, 7, 143-164.

Rodríguez, C.A. (2017). Los usuarios en su laberinto: burbujas de filtros, cámaras de ecos y mediación algorítmica en la opinión pública en línea. Virtualis, 8 (16), 57-76.

Rosales, M.B. (2018). Ciberactivismo: praxis feminista y visibilidad política en \#NiUnaMenos. Pléyade, 22, 63-85.

Sádaba, I. (2012). Acción colectiva y movimientos sociales en las redes digitales. Aspectos históricos y digitales. ARBOR. Ciencia, Pensamiento y Cultura, 188 (756), 781-794.

Sádaba, I. \& Barranquero, A. (2019). Las redes sociales del ciberfeminismo en España: identidad y repertorios de acción. Athenea Digital, 19 (1), e2058. https://doi. org/10.5565/rev/athenea.2058

Sádaba, I. \& Gordo, A. (2008). Cultura digital y movimientos sociales. Madrid: Los Libros de la Catarata.

Salaverría, R. (2017). Del periodismo móvil al ubicuo: allá donde estés, habrá noticias. Cuadernos de Periodistas, 35, 15-22.

Sampedro, V. (Ed.) (2005). 13 M multitudes on line. Madrid: Los Libros de la Catarata.

Sampedro, V. \& Resina, J. (2010). Opinión pública y democracia deliberativa en la Sociedad Red. Revista Ayer, 4, 139-162.

Sampedro, V. \& Sánchez, J. M. (2011). “La Red era la Plaza”. En Cibercampaña. Cauces y diques para la participación. Las elecciones generales de 2008 y su proyección tecnopolítica. Madrid: Editorial Complutense.

Sampedro, V., Sánchez, J. M. \& Politti, M. (2013). Ciudadanía y tecnopolítica electoral. Ideales y límites burocráticos a la participación digital. Co-Herencia, 10 (18), 105-136.

Soengas, X. (2013). El papel de Internet y de las redes sociales en las revueltas árabes: una alternativa a la censura de la prensa oficial. Comunicar, 41, 147-155.

Sorj, B. \& Fausto, S. (Comps.) (2016). Activismo político en tiempos de Internet. San Pablo: Plataforma Democrática.

Treré, E. \& Barranquero, A. (2013). De mitos y sublimes digitales: movimientos sociales y tecnologías de la comunicación desde una perspectiva histórica. Redes.com, 8, 27-47. 
Toret, J. (2013). Tecnopolítica: la potencia de las multitudes conectadas. El sistema red 15M, un nuevo paradigma de la política distribuida. Barcelona: UOC.

Toret, J. (coord.) (2015). Tecnopolítica y 15M. La potencia de las multitudes conectadas. Un estudio sobre la gestación y explosión del 15M. Barcelona: UOC.

Van Dijck, J. (2016). La cultura de la conectividad. Una historia crítica de las redes sociales. Buenos Aires: Siglo XXI.

Welp, Y. (2015). Cuando todo lo sólido se desvanece en Twitter. Análisis del Movimiento Social \#YOSOY132 (México 2012). Posdata, 20 (2), 417-439.

- Sobre la autoras:

Marina Acosta es Doctora en Ciencias Sociales (Universidad de Buenos Aires). Maestra en Comunicación (Universidad Iberoamericana Ciudad de México). Licenciada en Ciencias de la Comunicación (UBA). Investigadora del Instituto de Estudios de América Latina y el Caribe (UBA).

Agustina Lassi es Maestranda en Periodismo (Universidad de Buenos Aires). Licenciada en Comunicación Social por Universidad Nacional de La Matanza. Docente-Investigadora en la UNLaM y en la UNAJ.

- ¿Como citar?

Acosta, M. \& Lassi, A. (2019). Indignación online. La conversación digital del \#NiñasNoMadres en Argentina. Comunicación y Medios, (40), 200-213. 